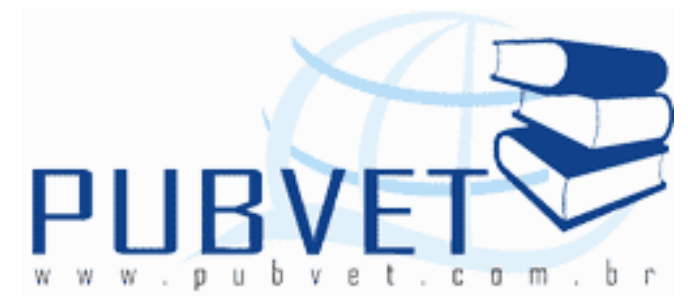

PUBVET, Publicações em Medicina Veterinária e Zootecnia.

\title{
Fenos e pré-secados
}

\section{Diego Lobon Jimenez Filho}

Médico Veterinário, Mestre em Zootecnia pela Universidade de São Paulo, Pirassununga-SP, Brasil. diegojimenez@usp.br

\section{Resumo}

Fenos e pré-secados são alimentos volumosos oriundos de diversas variedades de gramíneas ou leguminosas, de clima temperado ou tropical. Sua principal empregabilidade na nutrição de bovinos visa minimizar, os efeitos da estacionalidade de produção de forragens durante os meses secos do ano. Podem ser utilizados como volumosos principais ou complementares, com o intuito de fornecer fibras. Existem alguns métodos de processamento para os fenos, objetivando minimizar perdas durante o fornecimento e, aumentar a ingestão de matéria seca. O presente trabalho tem como objetivo elucidar as características nutricionais de forragens conservadas na forma de feno e silagens pré-secadas e, suas aplicabilidades na nutrição de bovinos.

Palavras-chave: Bovinos, FDN, Forragens, Nutrientes. 
JIMENEZ FILHO, D.L. Fenos e pré-secados. PUBVet, Londrina, V. 7, N. 25, Ed. 248, Art. 1639, Suplemento 1, 2013.

\section{Hay and haylage}

\section{Abstract}

Hay and haylage are coming from several varieties of grasses or legumes, temperate or tropical. Its main employability in the nutrition of cattle aims to minimize the effects of seasonal production of fodder during the dry months of the year. Can be used as main or additional bulky in order to provide primary fibers. There are some methods for processing hay, aiming to minimize losses during delivery and increase the intake of dry matter. The present work aims to elucidate the nutritional characteristics of forage conserved as hay and haylage, and their applicability in the nutrition of cattle.

Keywords: Cattle, NDF, Nutrients, Roughage.

\section{INTRODUÇÃO}

A estacionalidade da produção de forragens é reconhecida como um dos principais fatores responsáveis pelos baixos índices de produtividade da pecuária nacional. Práticas de conservação de forragens, tais como, fenação e silagens, são alternativas para solucionar ou minimizar o problema de falta de alimentos durante os meses críticos (Evangelista \& Tavares, 2009). Com a tendência de especialização da bovinocultura de leite e corte, tem se observado aumento no número de sistemas intensivos de produção, em que animais de alto potencial genético são mantidos em regime de confinamento, com a alimentação oferecida no cocho. A alimentação baseia-se, principalmente, em forragens conservadas como silagens e fenos, suplementadas com concentrados.

$O$ volume de nutrientes ingeridos e o desempenho animal dependem da quantidade e qualidade dos alimentos consumidos, porém, em ruminantes existem inúmeros fatores que interferem no consumo com intensidade de diferentes magnitudes. Os fatores que alteram a ingestão de alimentos são inerentes, ao animal, alimento, ambiente e, condições de manejo. A influência do alimento sobre o consumo de matéria seca está associada a composição em 
JIMENEZ FILHO, D.L. Fenos e pré-secados. PUBVet, Londrina, V. 7, N. 25, Ed. 248, Art. 1639, Suplemento 1, 2013.

gordura, relação concentrado:volumoso, teor de umidade e, fibra detergente neutro (FDN). Dietas pobres em FDN geralmente formuladas para animais de alta produção podem levar a ocorrências de problemas como acidose, laminite, além de redução do teor de gordura do leite. No entanto, dietas com altos níveis de fibras, impõem aos ruminantes, a necessidade de maior tempo de permanência do alimento no rúmen e, ampla capacidade ruminal em acomodar material de baixa densidade, para que, se processe uma fermentação adequada, consequentemente, há redução da eficiência do processo produtivo (NRC, 2001). Portanto, torna-se necessário o conhecimento dos efeitos, bem como da caracterização qualitativa e quantitativa dos alimentos comumente utilizados na alimentação dos bovinos, cujo objetivo final é a predição das respostas produtivas, para redução de custos, permitindo estratégias de manejo alimentar que resultem no incremento da produção.

\section{DEFINIÇÕES}

Feno

Feno é classificado como alimento volumoso, proveniente de forragens colhidas durante o período de crescimento, a qual é conservada seca para posterior utilização, geralmente quando há escassez de alimento volumoso (Ensmingeret al. 1990). O processo de fenação consiste em, colher a forragem com teor de umidade entre $65 \%$ e $85 \%$ e reduzi-lo para $10 \%$ a $20 \%$ (Ensmingeret al. 1990; Evangelista \& Tavares, 2009). A desidratação mais acentuada ocorre logo após o corte, diminuindo à medida que atinge valores abaixo de $65 \%$ de umidade, até atingir o ponto ideal. A rapidez com que o ponto de feno é obtido concorre para menores perdas de nutrientes (Evangelista \& Tavares, 2009).

\section{Pré-secado}

Pré-secado ou silagem pré-secada, são alimentos volumosos, conservados com umidade entre 40 e $60 \%$ sob fermentação e crescimento bacteriano limitado. O fator de maior importância na conservação do pré- 
JIMENEZ FILHO, D.L. Fenos e pré-secados. PUBVet, Londrina, V. 7, N. 25, Ed. 248, Art. 1639, Suplemento 1, 2013.

secado é a manutenção de baixa quantidade de oxigênio no interior dos fardos, rolos ou silos. Infiltração de ar no interior da silagem, resultado da vedação ineficiente, promoverá o crescimento de fungos e leveduras, levando ao aumento de temperatura e deterioração do alimento, o que é indesejável. Quando alimentos pré-secados são fornecidos aos animais, geralmente há aumento no consumo de matéria seca (Ensminger et al. 1990).

\section{PRINCIPAIS ESPÉCIES E VALORES NUTRITIVOS}

Feno

De maneira geral, muitas gramíneas podem ser conservadas na forma de feno (Tabela 1), como por exemplo: capim rhodes (Tamassia et al. 2001), estrela-africana, coastcross, tifton, pangola(Evangelista \& Tavares, 2009), tanzânia (Zanine et al. 2007), buffel (Souza \& Espíndola, 1999), quicuio(Cadorin Júnior, 2008), braquiárias (Fernandes et al. 2002) e outras. Dentre as leguminosas citam-se: soja perene (Ladeira et al. 2002), alfafa (Peixoto et al. 1999), leucena (Souza \& Espíndola, 1999) e outras, geralmente de porte rasteiro e hastes finas. A produção de fenos oriundos de forragens consorciadas (gramínea-leguminosa) se torna inviável, pois, a velocidade de desidratação é diferente, dificultando a obtenção do ponto de feno (Evangelista \& Tavares, 2009). 
JIMENEZ FILHO, D.L. Fenos e pré-secados. PUBVET, Londrina, V. 7, N. 25, Ed. 248, Art. 1639, Suplemento 1, 2013.

Tabela 1 - Valores nutricionais de fenos de gramíneas e leguminosas expressos em \%: (MS, PB, NDT, EE, FB, FDN, Ca e P) e Mcal/kg: (EB).

\begin{tabular}{|c|c|c|c|c|c|c|c|c|c|c|}
\hline Espécie & MS & PB & NDT & EB & EE & FB & FDN & $\mathbf{C a}$ & $\mathbf{P}$ & FONTE \\
\hline Alfafa & 89,12 & 19,08 & 58,53 & 4,43 & 2,34 & 29,38 & 47,59 & 1,29 & 0,23 & 1 \\
\hline Alfafa & 90,30 & 19,20 & 56,40 & ---- & 2,50 & ---- & 49,00 & 1,19 & 0,24 & 2 \\
\hline Aveia & 87,22 & 12,58 & 53,85 & 4,07 & 2,06 & 30,28 & 68,03 & 0,43 & 0,23 & 1 \\
\hline Aveia & 91,90 & 9,10 & 55,90 & ---- & 2,20 & ---- & 58,00 & 0,37 & 0,22 & 2 \\
\hline Aveia preta & 85,50 & 8,79 & ---- & 4,34 & ---- & ---- & 80,94 & ---- & ---- & 1 \\
\hline Azevém & 90,76 & 10,60 & ---- & ---- & ---- & ---- & 64,40 & ---- & ---- & 1 \\
\hline Azevém & 88,10 & 10,60 & 56,30 & ---- & 2,60 & ---- & 64,40 & 0,58 & 0,23 & 2 \\
\hline $\begin{array}{l}\text { B. decumbens } \\
31 \text { a } 45 \text { dias }\end{array}$ & 87,83 & 7,74 & ---- & ---- & 2,44 & 30,10 & ---- & ---- & ---- & 1 \\
\hline $\begin{array}{l}\text { B. decumbens } \\
121 \text { a } 150 \text { dias }\end{array}$ & 89,31 & 5,08 & ---- & ---- & 2,75 & 32,23 & ---- & ---- & ---- & 1 \\
\hline Coastcross & 88,90 & 8,39 & 52,69 & 4,25 & 1,45 & 34,00 & 79,18 & 0,47 & 0,21 & 1 \\
\hline Elefante & 86,99 & 6,36 & 52,49 & 3,31 & 2,03 & 34,73 & 79,99 & 0,29 & 0,18 & 1 \\
\hline Gordura & 87,50 & 3,49 & 22,30 & 4,42 & 1,23 & 37,75 & 81,79 & 0,36 & 0,10 & 1 \\
\hline Estrela & 89,03 & 11,53 & ---- & ---- & 2,38 & 33,20 & ---- & ---- & ---- & 1 \\
\hline Tanzânia & 86,81 & 7,65 & 34,54 & 3,99 & 1,59 & ---- & 70,03 & 0,60 & 0,04 & 1 \\
\hline $\begin{array}{l}\text { Tifton 85- } 0 \text { a } 30 \\
\text { dias }\end{array}$ & 83,19 & 17,56 & 59,49 & ---- & 1,28 & ---- & 79,50 & ---- & ---- & 1 \\
\hline $\begin{array}{l}\text { Tifton } 85-21 \text { a } \\
28 \text { dias }\end{array}$ & 87,30 & 13,70 & 55,30 & ---- & 2,70 & ---- & 76,90 & 0,39 & 0,22 & 2 \\
\hline $\begin{array}{l}\text { Tifton } 85-45 \text { a } \\
60 \text { dias }\end{array}$ & 83,89 & 11,63 & 55,90 & ---- & 0,84 & ---- & 81,96 & ---- & ---- & 1 \\
\hline Soja Perene & 88,40 & 14,70 & --- & 4,23 & 2,46 & 34,90 & 65,92 & 1,34 & 0,21 & 1 \\
\hline
\end{tabular}

Fontes: 1-(Valadares Filho et al. 2006). 2-(NRC, 2001). MS-(Matéria seca); PB-(Proteína bruta); NDT-(Nutrientes digestíveis totais); EB-(Energia bruta); EE-(extrato etéreo); FB-(Fibra bruta); FDN-(Fibra detergente neutro); Ca-(Cálcio); P-(Fósforo); ---- (sem dados).

\section{Pré-secado}

As forrageiras mais utilizadas para produção de silagem pré-secada, são as de clima temperado, como por exemplo: alfafa (Pereira \& Reis, 2001), aveia, azevém (Janssen, 2009), triticale e cevada. Entretanto, gramíneas tropicais como as do gênero Cynodonspp (Souza, 2004) e algumas braquiárias 
JIMENEZ FILHO, D.L. Fenos e pré-secados. PUBVet, Londrina, V. 7, N. 25, Ed. 248, Art. 1639, Suplemento 1, 2013.

(Evangelista \& Tavares, 2009) também são conservadas na forma de présecados. Os valores nutricionais das silagens pré-secadas, são altamente dependentes da qualidade do material que foi ensilado. Abaixo, valores nutricionais de algumas forrageiras conservadas pré-secadas (Tabela 2 ).

Tabela 2 - Valores nutricionais de pré-secados. (\%: MS, PB, NDT, EE, FB, FDN, Ca e P) e (Mcal/kg: EB).

\begin{tabular}{lccccccccc}
\hline Espécie & MS & PB & NDT & EE & FB & FDN & Ca & P & Fonte \\
\hline Alfafa & 48,87 & 16,30 & ---- & 1,88 & 31,08 & 46,90 & 0,81 & 0,32 & 1 \\
Alfafa & 44,10 & 19,50 & 63,00 & 3,70 & 25,40 & 47,50 & 1,32 & 0,31 & 2 \\
Tifton & 47,76 & 16,01 & 60,42 & 2,20 & ---- & 67,35 & 0,62 & 0,25 & 1 \\
Aveia preta & 32,40 & 12,42 & 54,48 & 2,89 & ---- & 60,10 & 0,71 & 0,33 & 1 \\
Azevém & 55,31 & 14,39 & 61,70 & 2,80 & ---- & 61,82 & 0,40 & 0,86 & 3
\end{tabular}

Fontes: 1-(Valadares Filho et al. 2006). 2-(NRC, 2000). 3-(Geron et al. 2010). MS-(Matéria seca); PB-(Proteína bruta); NDT-(Nutrientes digestíveis totais); EB-(Energia bruta); EE(extrato etéreo); FB-(Fibra bruta); FDN-(Fibra detergente neutro); Ca-(Cálcio); P-(Fósforo); --- (sem dados).

A escolha da espécie forrageira utilizada na produção de feno ou silagem pré-secada depende das condições climáticas da região, bem como, fertilidade do solo, tecnologia aplicada, exigências nutricionais dos animais e, economicidade do processo.

\section{RECOMENDAÇõES DE USO PARA BOVINOS E CARACTERÍSTICAS NUTRITIVAS}

Feno

Feno pode ser usado como alimento volumoso principal, ou complementar, em rações para bovinos. Porém, algumas espécies apresentam baixo valor nutritivo, os quais não suprem nutricionalmente os animais mais exigentes do rebanho (Gonçalves et al. 2003). O fornecimento pode ser feito por livre acesso ou limitado, dependendo, portanto, do tipo de feno (gramíneas ou leguminosas), da estratégia alimentar adotada (ração total ou volumoso e 
JIMENEZ FILHO, D.L. Fenos e pré-secados. PUBVet, Londrina, V. 7, N. 25, Ed. 248, Art. 1639, Suplemento 1, 2013.

concentrado separado), da categoria e exigências nutricionaisdos animais e, valor nutricional do feno (Ensminger et al. 1990).

Alguns métodos de processamento como picagem, moagem, cubagem e peletização, podem ser utilizados para fenos, com o propósito de minimizar perdas, aumentar a ingestão de matéria seca, diminuir poeira e facilitar o fornecimento aos animais (Udén, 1988; Beauchemin et al. 1997; Leonardi\&Armentano, 2003). A fina picagem e moagem dos fenos são indesejáveis para os bovinos, pois, reduzem a porção fisicamente efetiva da fibra, diminuindo proporcionalmente a produção de acetato no rúmen, consequentemente há queda no teor de gordura do leite produzido (Udén, 1988). Cubagem e peletização aumentam a taxa de passagem dos alimentos pelo trato gastrointestinal, sendo assim, bovinos alimentados com rações contendo alta porcentagem de volumoso (acima de $80 \%$ ) ou somente volumoso, podem consumir um terço a mais quando alimentados com feno cubado ou peletizado se comparados a bovinos consumindo feno longo ou picado (Udén, 1988; Beauchemin et al. 1997; Leonardi\&Armentano, 2003).

Segundo Hristov et al. (2001), a fermentação ruminal observada para dietas à base de feno de alfafa foi superior à de silagem de alfafa. Tal fato se dá pela maior disponibilidade do nitrogênio do feno aos microrganismos do rúmen, quando comparado à disponibilidade do nitrogênio da silagem de alfafa. Isso ocorreu, pois, o período de ação das enzimas proteolíticas da planta, foi maior sobre a forragem que sofreu desidratação, causando maior proteólise, elevando os teores de proteína solúvel do feno em relação aos teores dessa fração na alfafa ensilada (Mcdonald et al. 1983).

Yang et al. (1993) observaram que, o aquecimento moderado do feno de alfafa, reduz a degradação ruminal da proteína e melhora a utilização dessa fração pelos animais. As melhores taxas de escape proteico do rúmen foram obtidas quando, o feno de alfafa foi aquecido a $150^{\circ} \mathrm{C}$ por 120 minutos e a $160^{\circ} \mathrm{C}$ por 60 minutos, com ventilação forçada de ar seco, ou, à vapor por $30 \mathrm{a}$ 120 minutos a $100^{\circ} \mathrm{C}$ ou por 15 minutos a 112 ou $120^{\circ} \mathrm{C}$ de temperatura. 
JIMENEZ FILHO, D.L. Fenos e pré-secados. PUBVet, Londrina, V. 7, N. 25, Ed. 248, Art. 1639, Suplemento 1, 2013.

Gonçalves et al. (2003), trabalhando com feno de Tifton 85 em diferentes intervalos de corte $(28,42,63,84$ dias), obtiveram os respectivos valores de digestibilidade in vitro da matéria seca 59, 58,5,57,7 e 54,5\%. A digestibilidade da fração FDN foi $61,2 \%$ aos 28 dias de corte e $53 \%$ para fenos produzidos com 84 dias intervalo de corte $(P<0,05)$. Teores de proteína bruta $9,5 \%$ e $7,3 \%$ e, digestibilidade $60,9 \%$ e $47 \%$ para 28 e 84 dias de intervalo entre cortes respectivamente. Os valores das frações proteicas A e B1 sofreram decréscimo linear com o aumento da idade entre cortes $23 \%$ e $19,8 \%(p=0,00000)$ e, aumento linear dos valores da fração C 17,4\% e $22,8 \%$ $(p=0,00013)$ para 28 e 84 dias respectivamente. Com relação às frações de carboidratos, também houve queda linear dos valores das frações A e B1, $8,3 \%$ e 5,5\% (p=0,00003) e, aumento da fração $C, 10,9 \%$ e $14,3 \%$ $(p=0,00000)$ respectivamente para 28 e 84 dias.

\section{Pré-secado}

Pré-secados também são fornecidos aos animais como alimentos volumosos principais ou complementares. As silagens pré-secadas de gramíneas e leguminosas de clima temperado, apresentam em sua composição, menores teores e melhor qualidade da fração fibrosa, quando comparadas à pré-secados de forrageiras tropicais (Pereira et al. 2003). O teor proteico de pré-secados a partir de leguminosas, se equipara aos dos fenos (NRC, 2000; Valadares Filho et al. 2006; Geron et al. 2010). Pré-secados feitos de maneira adequada, apresentam aroma agradável e são mais palatáveis, tal fato pode explicar, o aumento no consumo de matéria seca, quando esse tipo de volumoso é fornecido aos animais (Ensminger et al. 1990).

Durante a pré-secagem das plantas, é comum a ocorrência de hidrólise parcial da fração proteica. Dessa maneira, durante o período de pré-secagem de 3 dias, mais de $20 \%$ do nitrogênio proteico em azevém, é convertido em nitrogênio não proteico. Entretanto, a taxa de conversão depende da velocidade de secagem. De 12 a 24 horas após a ensilagem, o conteúdo de nitrogênio não proteico da forragem pode aumentar de menos de $20 \%$ para 
JIMENEZ FILHO, D.L. Fenos e pré-secados. PUBVet, Londrina, V. 7, N. 25, Ed. 248, Art. 1639, Suplemento 1, 2013.

mais de $40 \%$ do nitrogênio total (Muck, 1988). No caso da alfafa, o teor de nitrogênio não proteico corresponde de 20 a 30\% do nitrogênio total e, após a ensilagem, chega a valores entre 40 e $85 \%$ (Nagel\& Broderick, 1992). Muck (1987) estudando o efeito do aumento do teor de matéria seca $(17,27,64$ e $73 \%$ ) sobre a fermentação e transformação do nitrogênio na silagem de alfafa, verificou que o aumento do teor de matéria seca da silagem diminui a concentração final de nitrogênio não proteico, aminoácidos livres e amônia, bem como a taxa inicial de proteólise após a ensilagem do material.

Rocha Júnior et al. (2003), obtiveram os seguintes valores de digestibilidade para pré-secado de tifton: $71,94 \%$ para proteína bruta, $67,78 \%$ para FDN. O teor de NDT, PB e FDN foram $60,49 \%, 16,73 \%$ e $67,06 \%$ da MS respectivamente. Lana et al. (2007), analisando degradação proteica de silagem pré-secada de capim braquiária com $28,6 \%$ de proteína bruta, conseguiram níveis de digestão de: 64,3\% para matéria seca, 29,6\% para proteína bruta e, suas frações, $11,9 \%$ A, 24,2\% B e 0,012\% C.

\section{ARMAZENAGEM}

O feno pode ser armazenado solto ou enfardado e, deve ser alocado em locais ventilados e livres de umidade. O armazenamento solto na forma de meda é menos oneroso, pois, não necessita de abrigo, reduz o custo com transporte e tem fácil acesso para o gado, porém, há perdas por lavagem e fermentação, diminuindo o valor nutritivo do volumoso. Na forma de fardos, o armazenamento pode ser feito em galpões, ou a campo coberto com lona. O material enfardado ocupa menos espaço, tem melhor conservação, facilita o transporte e possibilita o controle do estoque.Um bom feno deve apresentar cor esverdeada, semelhante ao da planta que o originou, odor agradável, ausência de bolores e elevada relação folha:caule (Evangelista \& Tavares, 2009).

Silagens pré-secadas são armazenadas em forma de rolos, fardos ou em silos, lembrando que, a condição de anaerobiose é essencial para a conservação da silagem. A armazenagem em fardos ou rolos apresenta como 
JIMENEZ FILHO, D.L. Fenos e pré-secados. PUBVet, Londrina, V. 7, N. 25, Ed. 248, Art. 1639, Suplemento 1, 2013.

vantagens, a facilidade de transporte, comercialização e, fornecimento aos animais. Segundo Van Soest (1994), a cor verde presente em silagens présecadas é alterada para vários tons de marrom, devido à intensidade de aquecimento durante o armazenamento, reação esta, denominada de, Maillard.

\section{CONSIDERAÇÕES FINAIS}

Fenos e pré-secados são alimentos volumosos ricos em fibras e podem ser empregados para complementar ou substituir outros volumosos como, por exemplo, silagem de milho, silagem de sorgo, cana-de-açúcar, tanto na alimentação de bovinos de corte como de leite. Os níveis de fornecimento de fenos ou pré-secados devem fornecem fibras suficientes para manter a saúde animal e ruminal.

A utilização de fenos e pré-secados para bovinos deve ser feita com base na viabilidade econômica, disponibilidade do volumoso na região ou na propriedade e, exigências nutricionais dos animais.

\section{REFERÊNCIAS BIBLIOGRÁFICAS}

Beauchemin, K.A., Rode, L.M. \&Eliason, M.V. 1997. Chewing activities and milk production of dairy cows fed alfalfa as hay, silage, or dried cubes of hay or silage. JournalofDairy Science. $80(2): 324-333$.

Cadorin Junior, R.L. 2008. Frequência de suplementação e fonte de nitrogênio suplementar e sua relação com 0 valor alimentar de dietas baseadas em feno de quicuio (Pennisetumclandestinum) fornecidas para ovinos. Dissertação de Mestrado, Universidade Federal de Santa Maria, Santa Maria, RS. 52p.

Ensminger, M.E., Oldfield, J.E. \& Heinemann, W.W. 1990. Feeds \& Nutrition. 2a ed. The Ensminger Publishing Company,Clovis, Califórnia. 1544p.

Evangelista, A.R. \& Tavares, V.B. 2009. Forrageiras - Formação e Utilização. FAEPE, Lavras, Minas Gerais. 168p.

Fernandes, L.O., Reis, R.A., Rodrigues, L.R.A., Ledic, I.L. \&Manzan, R.J. 2002. Qualidade do feno de BrachiariadecumbensStapf. submetido ao tratamento com amônia anidra ou uréia. Revista Brasileira de Zootecnia. 31(3):1325-1332.

Geron, L.J.V., Zeoula, L.M., Erkel, J.A., Prado, I.N., Bublitz, E. \& Prado, O.P.P. 2010. Consumo, digestibilidade dos nutrientes, produção e composição do leite de vacas alimentadas com resíduo de cervejaria fermentado. Acta Scientarum. Animal Science. 32(1):69-76. 
Gonçalves, G.D., Santos, G.T., Jobim, C.C., Damasceno, J.C., Cecato, U. \& Branco, A.F. 2003. Determinação do consumo, digestibilidade e frações proteicas e de carboidratos do feno de Tifton 85 em diferentes idades de corte. Revista Brasileira de Zootecnia. 32(4):804-8013.

Hristov, A.N., Huhtanen, P., Rode, L.M., Acharya, S.N. \&Mcallister, T.A. 2001. Comparison of the ruminalmetabolismo of nitrogen from $15 \mathrm{~N}$-labeled alfalfa preserved as hay or as silage. JournalofDairy Science. 84:2738-2750.

Janssen, H.P. 2009. Adubação nitrogenada para rendimento de milho silagem em sucessão ao azevém pastejado, pré-secado e cobertura em sistemas interados de produção. Dissertação de Mestrado, Universidade Federal do Paraná, Curitiba, PR. 91p.

Ladeira, M.M., Rodriguez, N.M., Borges, I., Gonçalves, L.C., Saliba, E.O.S., Brito, S.C. \& Sá, L.A.P. 2002 Avaliação do feno de Arachispintoi utilizando o ensaio de digestibilidade In vivo. Revista Brasileira de Zootecnia. 31(6):2350-2356.

Lana, R.P., Leopoldino, W.M., Oliveira, J.S., Veloso,R.G., Nunes, P.M.M. \& Queiroz, A.C. 2007. Parâmetros da degradação proteica ruminal de diferentes alimentos e rações estimados por técnica in vitro. Arquivo Brasileiro de Medicina Veterinária e Zootecnia. 59(2):414-422.

Leonardi, C. \&Armentano, L.E. 2003. Effect of quantity, quality, and length of alfalfa hay on selective consumption by dairy cows. Journal of Dairy Science.86(2):557-564.

Mcdonald, P., Proven, M.J. \& Henderson, A.R. 1983. The effect of some pre-ensiling treatments on silage composition and nitrogen disappearance in the rúmen. Animal Feed Science and Technology. 8(4):259-269.

Muck, R.E. 1987. Dry matter level effects on alfalfa silage quality. I. Nitrogen transformations. American Society of Agricultural and Biological Engineers. 30(1):7-14.

Muck, R.E. 1988. Factors influencing silage quality and their implications for management. Journal of Dairy Science. 71(11):2992-3002.

Nagel, S.A. \& Broderick, G.A. 1992. Effect of formic acid or formaldehyde treatment of alfalfa silage on nutrient utilization by dairy cows. Journal of Dairy Science. 75(1):140-154.

National Research Council. 2000. Nutrient Requirements of Beef Cattle. 7a ed. Update. National Academy Press, Washington, 232p.

National Research Council. 2001. Nutrient Requirements of Dairy Cattle. 7a ed. National Academy Press, Washington, 381p.

Peixoto, A.M., Moura, J.C., Silva, S.C. \&Faria, V.P.1999. Alfafa. Anais 16Simpósio sobre Manejo da Pastagem, Piracicaba, SP. 223p.

Pereira, J.R.A. \& Reis, R.A. 2001 Produção de silagem pré-secada com forrageiras temperadas e tropicais. Anais Simpósio sobre Produção e Utilização de Forrageiras Conservadas, Maringá, PR. p.64-86.

Pereira, E.S., Arruda, A.M.V., Mizubuti, I.Y., Queiróz, A.C., Krapp, A., Syperreck, M.A. \& Barreto, J.C. 2003. Efeito de diferentes volumosos conservados na forma de silagem sobre a ingestão de alimentos e produção de leite de vacas em lactação. Semina: Ciências Agrárias. 24(1):103-112. 
Rocha Júnior, V.R., Valadares Filho, S.C., Borges, A.M., Magalhães, K.A., Ferreira, C.C.B., Valadares, R.F.D. \& Paulino, M.F. 2003. Determinação do valor energético de alimentos para ruminantes pelo sistema de equações. Revista Brasileira de Zootecnia. 32(2):473-479.

Souza, A.A. \& Espíndola, G.B. 1999. Efeito da suplementação com feno de leucena (Leucaenaleucocephala (Lam) de Wit) durante a estação seca sobre o desenvolvimento ponderal de ovinos. Revista Brasileira de Zootecnia. 28(6):1424-1429.

Tamassia, L.F.M., Haddad, C.M., Castro, F.G.F., Vendramini, J.M.B. \& Domingues, J.L. Produção e morfologia do capim Rhodes em seis maturidades. Scientia Agricola. 58(3):599605.

Udén, P. 1988. The effect of grinding and pelleting hay on digestibility, fermentation rate, digesta passage and rumen and faecal particle size in cows. Animal Feed Science and Technology. 19(1-2):145-157.

Valadares Filho, S.C., Magalhães, K.A., Rocha Júnior, V.R. \&Capelle, E.R. 2006. Tabelas brasileiras de composição de alimentos para bovinos. $2^{a}$ ed. GráficaSuprema, Viçosa, 329p.

Van Soest, P.J. 1994. Nutritional ecology of the ruminant.Comstock Publishing, Ithaca, 476p.

Yang, J.H., Broderick, G.A. \&Koegel, R.G. 1993. Effect of heat treating alfalfa hay on chemical composition and ruminal in vitro protein degradation. JournalofDairy Science. 76(1)154-164.

Zanine, A.M., Santos, E.M., Ferreira, D.J. \& Pereira, O.G. 2007. Efeito de níveis de uréia sobre o valor nutricional do feno de capim-Tanzânia. Semina: Ciências Agrária. 28(2):333-340. 